\title{
The emerging role of the androgen receptor in bladder cancer
}

\author{
Alan P Lombard ${ }^{1,2,3}$ and Maria Mudryj ${ }^{1,2}$ \\ ${ }^{1}$ Veterans Affairs-Northern California Health Care System, Mather, California, USA \\ ${ }^{2}$ Department of Medical Microbiology and Immunology, and ${ }^{3}$ Biochemistry, Molecular, Cellular, and \\ Developmental Biology Graduate Group and Biotechnology Program, University of California, 1 Shields Avenue, \\ Tupper Hall 3147, UC Davis, Davis, California 95616, USA
}

Correspondence

should be addressed

to M Mudryj or A Lombard

Emails

mmudryj@ucdavis.edu or

aplombard@ucdavis.edu

\begin{abstract}
Men are three to four times more likely to get bladder cancer than women. The gender disparity characterizing bladder cancer diagnoses has been investigated. One hypothesis is that androgen receptor (AR) signaling is involved in the etiology and progression of this disease. Although bladder cancer is not typically described as an endocrine-related malignancy, it has become increasingly clear that AR signaling plays a role in bladder tumors. This review summarizes current findings regarding the role of the AR in bladder cancer. We discuss work demonstrating AR expression in bladder cancer and its role in promoting formation and progression of tumors. Additionally, we discuss the therapeutic potential of targeting the AR in this disease.
\end{abstract}

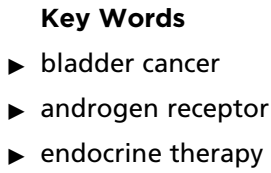

Endocrine-Related Cancer (2015) 22, R265-R277

\section{Introduction}

Bladder cancer in the US is estimated to account for $\sim 74000$ new cases of cancer and $\sim 16000$ deaths in 2015 (Siegel et al. 2012). Overall, $>90 \%$ of bladder cancer cases are urothelial cell carcinomas which are malignancies of the specialized transitional epithelium lining the organ (Crallan et al. 2006). Urothelial cell carcinomas of the bladder (UCCB) are classified into two categories; nonmuscle invasive and muscle invasive (Knowles \& Hurst 2015). Though non-muscle invasive disease is more prevalent and very treatable, tumor recurrence is common which can lead to invasion (Carneiro et al. 2015). Muscle invasive bladder cancer is far more problematic with a higher likelihood of metastasis that ultimately leads to death (Knowles \& Hurst 2015). Treatment options for metastatic bladder cancer include chemotherapy regimens such as methotrexate, vinblastine, doxorubicin, and cisplatin (MVAC) and gemcitabine and cisplatin (GC) (Kim 2012). However, despite positive responses in some individuals, patients succumb to the disease due to the development of resistance (Wen et al. 2015). Research is ongoing to better understand the molecular mechanisms of this disease so that novel treatments can be identified (Carneiro et al. 2015). Despite these efforts, treatment options have remained largely unchanged for the past 30 years thus demonstrating the need for further studies on the factors driving this malignancy (Powles et al. 2014).

Further complicating our understanding of bladder cancer is the gender disparity that characterizes its diagnosis. Men are three to four times more likely to develop bladder cancer than women (Siegel et al. 2012). Reasons proposed for this disparity have been thought to include environmental as well as lifestyle factors such as smoking (Hartge et al. 1990). However, further investigation that controlled for these variables still showed that there is a higher likelihood for men to develop bladder cancer than women (Hartge et al. 1990). Although bladder cancer is not traditionally thought of as an endocrinerelated cancer, the theory that the androgen receptor (AR)

Published by Bioscientifica Ltd 
and androgen signaling is involved in the etiology and progression of this disease has been proposed.

The AR is a steroid hormone receptor with a size of $110 \mathrm{kD}$ responsible for mediating androgen (i.e., testosterone, dihydrotesterone) signaling (Fig. 1) (Proverbs-Singh et al. 2015). The AR functions as a transcription factor. When bound to androgen, the AR is released from heat shock proteins (HSP), becomes phosphorylated, forms a homodimer, and translocates from the cytoplasm to the nucleus. In the nucleus, the AR binds to androgen response elements in the genome, and along with co-regulators, controls gene transcription (Mudryj \& Tepper 2013). Alternative mechanisms which activate the AR in the absence of androgens also exist. Signals initiated by other receptors such as epidermal growth factor receptor (EGFR) can lead to activation of the AR independent of androgen (Lamont \& Tindall 2011). Additionally, low molecular weight AR isoforms missing the ligand binding domain can signal without androgen (Devlin \& Mudryj 2009).

Androgen signaling has been linked to regulation of proliferation, motility, and cell death (Culig \& Santer 2012). The AR has been shown to play a role in malignancies of the prostate, kidney, lung, breast, and liver (Chang et al. 2014). The AR's role in oncology is best described in prostate cancer where it plays a critical role in all stages of tumorigenesis. Recent studies suggest that there is a higher than expected association between prostate cancer and bladder cancer (Marcinkiewicz et al. 2012). This suggests that AR signaling may be one

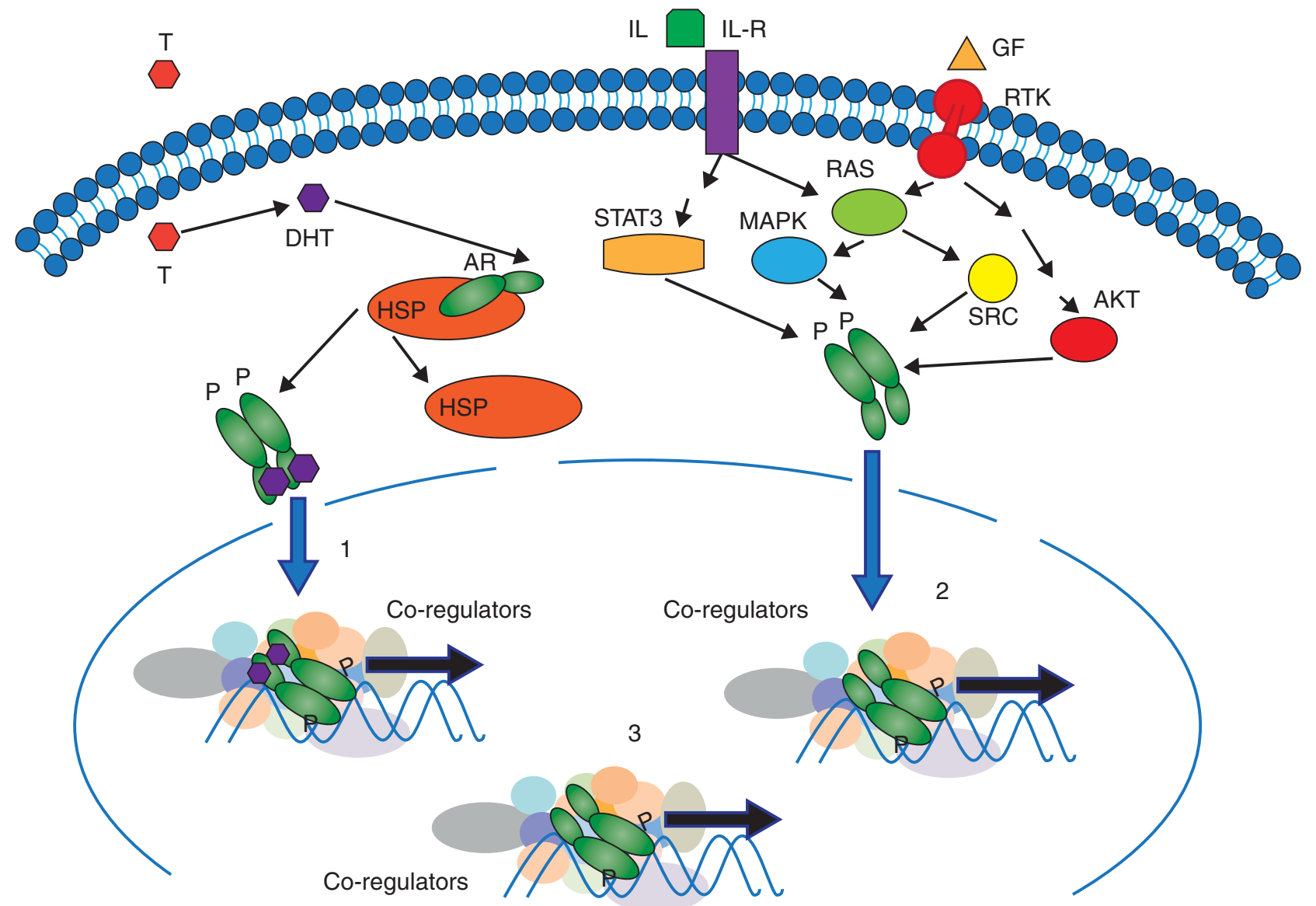

\section{Figure 1}

The basic mechanisms of AR signaling. (1) The canonical mechanism, where testosterone (T) interaction with the heat shock protein (HSP)-bound AR results in an AR confirmation change, dissociation from the HSP, phosphorylation, dimerization, and translocation into the nucleus, where the $A R$, in concert with co-regulators promotes gene transcription. (2) In an alternative mechanism, AR co-regulators, including kinases, interact with the AR to modify its confirmation driving its dissociation from HSPs, translocation into the nucleus, interaction with co-regulators, and promotion of gene transcription. (3) In a mechanism described in prostate cancer, a truncated AR molecule that is missing the ligand binding domain can translocate into the nucleus in the absence of ligand and along with co-regulators promote gene expression. 
mechanism that contributes to bladder cancer development. To explore the possible role of AR in bladder cancer, several labs have defined AR expression patterns and function in this disease. These studies argue that the AR is involved in the etiology and progression of bladder cancer. However, a complete understanding of the AR in bladder cancer and what this information means clinically is still needed.

In this review, we will provide an overview of the landscape pertaining to the AR's role in bladder cancer. First, research showing AR function in normal bladder tissue will be presented to demonstrate its role and function in this organ. We will then present work highlighting AR expression and function in experimental models and in human bladder tumors. Additionally, we will review the molecular mechanisms by which the AR may promote bladder cancer and, finally, we will discuss the therapeutic implications of AR's role in bladder tumorigenesis.

\section{Role of the AR in urothelial development and normal bladder function}

Studies on the development of the internal male genital organs found that the prostate, bladder, membranous parts of the urethra, and bulbourethral gland are all derived from the endoderm of the urogenital sinus (Mizuno 1994, Thomas et al. 2008). The development of the prostate is dependent on the presence of androgens whose action is mediated by the AR. Therefore the urogenital sinus expresses the AR (Mizuno 1994). Studies on the expression of AR in adult tissues were initiated following the cloning of the AR and the development of AR specific antibodies that could be used in immunohistochemical analysis (Chang et al. 1988, Lubahn et al. 1988, Trapman et al. 1988). Once these tools became available, several laboratories reported that the AR is expressed not only in tissues that were known to be sensitive to androgens but in multiple tissues that were not thought to be androgen regulated (Ruizeveld de Winter et al. 1991, Kimura et al. 1993). These studies demonstrated that AR was expressed widely throughout the body including in the liver, gastrointestinal tract, and the bladder. Interestingly, $\mathrm{AR}$ was expressed exclusively in the nucleus, suggesting that it could be functioning as a transcription factor thus regulating cellular processes (Kimura et al. 1993).

Studies in animal models have been instrumental in defining the role of AR in bladder physiology. In the lower urinary tract of male rats, the $\mathrm{AR}$ is present in the urothelium, bladder smooth muscle cells, proximal urethra striated muscle cells, and neurons in the autonomic ganglia of the prostatic plexus suggesting that androgens could have a direct effect in the lower urinary tract (Salmi et al. 2001). In a study of juvenile male rats subjected to bilateral orchiectomy or bilateral orchiectomy followed by supplementation with testosterone, the presence of testosterone was associated with increased bladder mass and increased bladder smooth muscle mass, supporting the notion that hormones have a role in the development of these tissues (Shortliffe et al. 2014). The rat model was also used to study the effect of androgens on the autonomic neurons that supply pelvic visceral organs. In the castrated animals, noradrenergic pelvic neurons that supply the vas deferens, prostate gland, urinary bladder, and colon were only $\sim 60 \%$ the size of those in intact control animals (Keast \& Saunders 1998). From the previously mentioned studies, we can conclude that the AR and androgens have a role in the development and physiology of bladder tissue in males. These studies make it plausible that altered AR expression and function may be involved in the etiology and progression of bladder cancer.

\section{Role of AR in bladder carcinogenesis}

Radical cystoprostatectomy is one surgical approach for male patients with muscle invasive bladder cancer and includes removal of the prostate. Several studies have evaluated the prostatic tissue from these surgeries and found prostate cancer or high grade prostatic interstitial hyperplasia was detectable in $\sim 30-50 \%$ of the tissues (Alsinnawi et al. 2012, Fritsche et al. 2012, Nevoux et al. 2012, Bruins et al. 2013, Ahmadi et al. 2014). While most of the prostate cancers were low grade, one large study reported that $22 \%$ were clinically significant (Bruins et al. 2013). Most bladder cancer patients are of advanced age, hence it is not altogether surprising that there was a high incidence of low grade prostate cancer. However, it is notable that one study reported the presence of prostatic carcinomas, particularly carcinoma with stromal involvement, was associated with a worse prognosis (Bruins et al. 2013). This observation suggested that a common factor or factors contribute to both malignancies. It is arguable that the $\mathrm{AR}$, a pivotal molecule in the development and progression of prostate cancer, may be this factor.

In an effort to determine the role of the $\mathrm{AR}$ in bladder cancer, several labs have demonstrated, using animal models, that alteration of AR expression and signaling affect tumor formation. Early studies utilized

Published by Bioscientifica Ltd. 
$N$-butyl- $N$-(4-hydroxybutyl) nitrosamine (BBN) to induce tumors in rats in the presence or absence of testosterone (Okajima et al. 1975). This study determined that testosterone promoted bladder carcinogenesis in female rats (Okajima et al. 1975). Interestingly, this same group found that the anti-estrogen diethylstilbestrol inhibited carcinogenesis and progression of bladder tumors in male rats (Okajima et al. 1975). Studies which utilized $\mathrm{N}$-nitrosobis(2-oxopropyl)amine (BOP) to induce prostate tumors in rats revealed that testosterone promoted urothelial carcinoma formation, and conversely, orchiectomy reduced the incidence of bladder tumor formation (Pour \& Stepan 1987). Further analysis demonstrated that BBN-induced bladder carcinogenesis could be altered by modifying testosterone signaling using luteinizing hormone-releasing hormone (LH-RH) analogues (Matsuki et al. 1989, 1992). Since BBN was shown not to effect testosterone levels, the LH-RH analogues are responsible for observed changes in hormone levels (Matsuki et al. 1989). In female rats, testosterone administration promoted bladder tumor formation in intact rats but not in oophorectomized rats, suggesting that testosterone signaling in conjunction with estrogen signaling play a role in bladder cancer formation (Terada et al. 1992).

A robust study tested not only castration and LH-RH agonists but also the AR antagonist flutamide and the $5 \alpha$-reductase (an enzyme that converts testosterone to $5 \alpha$-dihydrotestosterone) inhibitor Finasteride (Imada et al. 1997). Flutamide was shown to inhibit bladder tumor incidence in a dose dependent manner while Finasteride showed no difference. This result argues that testosterone might have a potent effect on bladder carcinogenesis but that conversion of testosterone to the more active form, $5 \alpha$-dihydrotestosterone, does not occur in this model.

Bypassing the need for chemical induction of tumors, Johnson et al. (2008) demonstrate similar findings to the preceding using a transgenic mouse model of bladder tumorigenesis. UPII-SV40T mice express the SV-40 $\mathrm{T}$ antigen (tumor virus protein that inhibits functioning of p53 and pocket proteins) exclusively in the urothelium and reliably develop bladder tumors (Johnson et al. 2008). Using this model, the authors show that castration inhibits tumor growth (Johnson et al. 2008).

The previous lines of evidence support the role of testosterone in bladder carcinogenesis, but fail to demonstrate that it is AR mediated. One study found that unilateral orchiectomy actually promoted BBN induced bladder carcinogenesis in male rats (Saikawa et al. 2001). Although these data seem contradictory to previous reports, the study noted that AR protein expression was higher following unilateral orchiectomy (Saikawa et al. 2001). Thus, it is possible that despite orchiectomy, increased AR levels could compensate for decreased testosterone levels. Increased AR expression is one mechanism that results in continued proliferation of prostate cancer cells in castrate levels of androgen (Devlin \& Mudryj 2009). Thus, the increased AR expression in bladder cells could be directly involved in bladder carcinogenesis.

Studies have also directly addressed the importance of AR in bladder cancer development. Miyamoto et al. (2007) demonstrated that AR knockout (ARKO) mice do not get BBN induced tumors. Interestingly, they also found that BBN did induce tumors in $25 \%$ of ARKO mice supplemented with dihydrotestosterone (DHT) (Miyamoto et al. 2007). BBN induced tumors in 50\% of castrated WT mice (Miyamoto et al. 2007). These results strongly suggest that AR is key in bladder carcinogenesis. The ARKO mice were generated by a disruption of exon 2 of the AR gene, which encodes the second zinc finger of the AR DNAbinding domain. The result that DHT supplementation in the ARKO mice induces tumor formation argue that, i) while an AR molecule that is missing one zinc finger has greatly diminished AR activity, enough residual activity remains, so that supplementation with DHT can partly restore AR signaling or ii) that androgens exert an effect on cells by a mechanism that is independent of AR. In a study where the AR was ablated only in urothelial tissue, bladder tumor development decreased and there was a prolonged survival in animals that developed tumors (Hsu et al. 2013). These data differ from those generated using a total body AR KD detailed previously, suggesting that the activity of the AR in other tissues also regulates tumor formation. Furthermore, this study showed that overexpression of the AR in the immortalized but nontransformed urothelial cell line SV-HUC-1 promoted chemically-induced tumorigenesis (Hsu et al. 2013). In a $\beta$-catenin driven mouse model of bladder tumorigenesis, males developed tumors at a rate of $45 \%$ compared to $3 \%$ of females (Lin et al. 2013). Males showed AR nuclear translocation while females in general showed much weaker AR staining (Lin et al. 2013). Further analysis revealed that nuclear translocation of the AR is critical for tumor development in these mice, arguing that an interaction between $\beta$-catenin and AR is instrumental in the development of this neoplasia (Lin et al. 2013).

Exposure to carcinogens, such as cigarette smoke and industrial chemicals, had been suggested to be a cause for high incidence of bladder cancer in men. UDP-glucuronosyltransferases (UGTs) play a major role in the

Published by Bioscientifica Ltd 
elimination of numerous carcinogens by transporting and sequestering these substances (Bock 2010). The urinary bladder is the main pathway for excretion of glucuronides and bladder cells express all the subtypes of UGTs except UGT2B17 (Nakamura et al. 2008). In an immortalized urothelial cell line transfected with an AR expression plasmid, treatment with androgens reduced the expression of all UGT1A subtypes and treatment with hydroxyflutamide, an AR antagonist, partly reversed this effect. An analysis of bladder tissues from ARKO mice showed that the expression of all the UGT1A genes were upregulated (Izumi et al. 2013). Likewise, castration of male mice resulted in increased UGT1A expression, confirming AR-dependent repression of these detoxification genes (Izumi et al. 2013). Expression of UGT1A was lower in human tumor tissue, than in normal urothelial cells, and although not statistically significant, there was an inverse correlation between UGT1A and AR expression (Izumi et al. 2013). These data suggest that AR-mediated repression of UGTs may decrease the inactivation of carcinogens and thus could play a role in promoting bladder tumorigenesis.

Together, the previously reviewed studies strongly indicate that $\mathrm{AR}$ is a participant in bladder tumorigenesis. Much of the presented data suggests that androgen signaling promotes the formation of both male and female bladder tumors. These data are consistent with two possible hypotheses regarding male vs female bladder cancer incidence; i) Males have higher AR expression or ii) higher levels of circulating androgens predispose to bladder cancer (Izumi et al. 2014).

\section{Expression of the AR in human bladder cancer}

In recent years, a number of studies sought to define the expression of AR in human bladder cancers and to determine if differences in expression correlate with various aspects of the disease. Early studies demonstrated that $\mathrm{AR}$ was present in bladder cancer tissue and that $\mathrm{AR}$ was present at higher levels in tumor tissue than in control tissue suggesting upregulation of AR in malignancy (Laor et al. 1985). Subsequent studies supported these results demonstrating that the AR was expressed in bladder tumor tissue and that AR expression is notably higher in tumor tissue than in non-tumor tissue (Noronha \& Rao 1986, Zhuang et al. 1997, Mir et al. 2011, Mashhadi et al. 2014, Mohanty et al. 2014, Williams et al. 2015). An analysis using western blots showed that in addition to the full length $\mathrm{AR}$, other AR isoforms ( 90 and $60 \mathrm{kD}$ ) could be detected in tumors (Zhuang et al. 1997). Thus, AR has been detected in bladder cancer tumors in a number of studies but the contribution of AR expression to the progression of this disease is not fully understood.

A study by Mashhadi et al. (2014) demonstrated that AR expression positively correlated with tumor stage and grade and that patients with AR-positive tumors had a poorer prognosis than those with AR-negative tumors. This study also reported that AR-positivity is associated with metastasis. An analysis of non-metastatic and metastatic tumors found that a higher percentage of metastatic lesions expressed AR than primary tumors (Miyamoto et al. 2012). Additional studies reported that AR expression is detected in a higher percent of invasive tumors (15.1\%) vs non-invasive tumors (9\%) and that AR expression correlated with tumor progression (Zheng et al. 2011). These data suggest that AR expression is positively correlated with disease progression.

In contrast, conflicting studies argue that AR expression actually decreases with increasing stage and grade of disease indicating low AR expression is associated with progression and invasion (Laor et al. 1985, Boorjian et al. 2004, Tuygun et al. 2011, Miyamoto et al. 2012, Gakis \& Stenzl 2013). One study reported that while AR levels were more often detected in invasive tumors, this did not affect tumor recurrence and did not correlate with time to death or death from disease (Mir et al. 2011). Of note, it was shown that carcinoma in situ (CIS) tumors were an outlier possessing lower AR expression than pT1 tumors (Boorjian et al. 2004). Interestingly, one study also showed that none of the control tissue samples expressed AR while $\sim 51 \%$ of tumors did show expression (Tuygun et al. 2011). This suggests that although AR may decrease with disease progression, AR upregulation may occur in certain stages of tumorigenesis. However, the overall contribution of AR expression to bladder cancer remains controversial.

Some investigations sought to determine if AR expression is significantly different in male tumors vs female tumors. One study found that AR levels in male tumor tissue were higher than that found in female tumor tissue suggesting a mechanism that explains the discrepancy in the incidence of bladder cancer in males and females (Laor et al. 1985). This data is supported by the study of $\beta$-catenin induced bladder tumorigenesis where AR was more highly expressed in male mouse tumors and shown to factor into tumor progression (Lin et al. 2013). Additionally, studies in some female patients revealed that the Xq11-12 locus containing the active AR gene is deleted in some tumors and $\mathrm{X}$ chromosome inactivation occurs in others (Cheng et al. 2004). Thus, although AR expression and signaling may predispose men to bladder cancer over

Published by Bioscientifica Ltd 
females, AR expression may be less involved in bladder tumorigenesis in females than in males (Cheng et al. 2004). The previous studies are challenged by more recent studies which argue that the AR was expressed at similar levels in both male and female patients, and that there was no statistically significant difference in AR expression between male and female tumors (Laor et al. 1985, Mir et al. 2011, Tuygun et al. 2011, Mashhadi et al. 2014). Therefore, the role of the AR in male vs female bladder tumors is unresolved.

In summary, the AR has been detected in human bladder cancer in a number of studies but there is no clear consensus on whether its expression level is important in bladder cancer progression. The data overall suggest that AR expression is frequently upregulated in early stages of bladder cancer but sometimes decreases as the disease progresses. Bladder cancer, like other cancers, is a heterogeneous group of diseases and dependence on AR for later stages of disease may vary from patient to patient. The AR does not appear to be a good bladder cancer prognosticator at this time. Whether the AR makes a viable therapeutic target may depend on stage and the particular patient's unique tumor.

The data suggests that AR does not differentiate between male and female tumors. One hypothesis that resolves these discrepancies is that androgen signaling, rather than AR levels, is primarily responsible for the discrepancy between male and female incidence of bladder cancer (Izumi et al. 2014). Although the AR can be variably expressed and seems to play a role in the disease, males have higher circulating androgen than do females. Therefore, the high level of circulating androgen, and thus AR activity, may be central to predisposing males to bladder cancer. However, it is most likely that some combination of elevated androgen signaling and AR levels play a role in this disease. In the following sections, we will delve into the literature pertaining to the mechanistic functions of the AR in bladder cancer and examine the therapeutic implications.

\section{AR, co-regulators, and collaborating signaling pathways in bladder cancer}

Several studies investigated the expression of known AR co-regulators and their clinical significance. Previous studies of AR coregulators were conducted in the context of prostate cancer and the results differed in bladder tumor studies (Boorjian et al. 2009). AR and its coregulators NCOA1, NCOA2, NCOA3, CREBBP, and EP300 were expressed at varying degrees in both bladder tumor samples and in the TCC-SUP and UM-UC-3 UCCB cell lines (Boorjian et al. 2009). Interestingly, it was determined that siRNA-mediated inhibition of several co-factors investigated decreased viability of bladder cancer cells (Boorjian et al. 2009). However, the study noted that only NCOA1 levels were significantly lower in tumor tissue vs control tissue (Boorjian et al. 2009). Consistent with previous studies, this analysis also reported that $A R$ trended toward upregulation in tumor tissue (Laor et al. 1985, Boorjian et al. 2009, Miyamoto et al. 2012, Mashhadi et al. 2014). Despite this trend, AR was also found to decrease with increasing stage of disease (Boorjian et al. 2009).

An investigation of AR expression along with two chromatin modifying coregulators, lysine-specific demethylase 4A (JMJD2A) and lysine-specific histone demethylase 1A (LSD1) showed that both AR and JMJD2A expression decreased in tumor tissue when compared to benign tissue, while LSD1 levels increased (Kauffman et al. 2011). However, all three proteins were found to decrease with progression of the disease (Kauffman et al. 2011). JMJD2A expression additionally correlated with lymphovascular invasion, concomitant CIS, tobacco usage, and decreased overall survival (Kauffman et al. 2011).

Cyclin D1, the regulatory subunit of the cyclin D1/CDK4/6 kinase complex, phosphorylates RB to promote cell cycle progression. However, in the context of prostate cancer, the interaction of cyclin D1 with AR inhibits AR activity (Petre-Draviam et al. 2003). This effect of cyclin D1 on AR has also been detected in T24 bladder cells, suggesting that this interaction is not prostate specific (Petre-Draviam et al. 2003). A meta-analysis of 15 studies on cyclin D1 expression and bladder tumorigenesis revealed that increased cyclin D1 levels significantly associated with progression-free survival (Ren et al. 2014). A cyclin D1 splice variant, cyclin D1b, has been found to be oncogenic in prostate cancer and regulates a transcriptional network that in concert with the AR, enhances proliferation and invasion (Augello et al. 2013). At this time, it is unknown if bladder tumors express this cyclin D1b splice variant and if it functions in a similar manner to promote bladder tumorigenesis.

The AR works in concert with other signaling pathways to promote tumorigenesis, often directly interacting with key molecules. $\beta$-catenin has been shown to correlate with tumor progression and poor clinical outcomes in patients with bladder cancer, and immunohistochemical studies of bladder tumors identified a strong correlation between nuclear AR expression and $\beta$-catenin (Li et al. 2013).

Published by Bioscientifica Ltd 
Androgen treatment of AR-expressing cells promoted $\beta$-catenin translocation into the nucleus and its transcriptional activity. Co-immunoprecipitation studies indicated that in bladder tumor derived cell lines, $\beta$-catenin physically interacts with the AR (Li et al. 2013).

The AR interacts with the EGFR signaling pathway to exert an effect on bladder tumor cell physiology. An immunohistochemical study of bladder tumors showed a strong association between expression of AR and the EGFR, phospho-EGFR, and ERBB2 (Zheng et al. 2011). Further analysis in AR expressing bladder tumor derived cell lines indicated that treatment with androgens resulted in increased expression of EGFR and ERBB2 at the mRNA and protein levels (Zheng et al. 2011). Conversely, shRNA mediated AR ablation reduced EGFR and ERBB2 levels (Zheng et al. 2011). Additionally, treatment of the cells with androgens increased phosphorylation of EGFR and its downstream targets AKT and ERK1/2, suggesting that AR may have a role in activating the EGFR signaling pathway (Zheng et al. 2011). Further studies on the interaction between AR and EGFR found that the EGFR inhibitor PD168393 antagonized the effect of androgen treatment on AR transcriptional activity (Hsieh et al. 2013). Treatment of cells with an AR antagonist abolished the effects of both proteins (Hsieh et al. 2013). EGF treatment promoted the association of AR with estrogen receptor- $\beta$ or with SRC, suggesting that EGFR activates AR by promoting complex formation (Izumi et al. 2012). These studies argue that there is a complex reciprocal regulation between the EGFR and AR signaling pathways and that targeting both may be efficacious in the treatment of certain malignancies.

Clearly, the AR functions in a number of ways and interacts with many pathways. The data previously presented regarding $\beta$-catenin signaling, cyclin-d1 interactions, and growth factor cross-talk with the AR bring up the interesting hypothesis that cell-cell communication in the tumor microenvironment may be instrumental in altering AR signaling in bladder cancer. One study performed by Turkeri et al. (1998) demonstrates that EGF and TGF- $\alpha$ were expressed in the stroma and around vessels found within tumor samples. Thus, it is possible that factors derived from other cell types may influence AR signaling to promote tumor progression. However, this notion requires further study.

\section{The AR, genetic variation, and bladder cancer}

Genomic instability of the AR gene has been detected in bladder cancer and data suggest that this may be involved in disease progression. A highly polymorphic trinucleotide (CAG) repeat, or polyglutamine expansion (polyGln), is present in the AR gene (Allen et al. 1992). Investigation of the role of the polyGln region has shown that its size inversely correlates with AR transactivation function (Kazemi-Esfarjani et al. 1995). Moreover, studies have demonstrated that the polyGln region in the AR gene locus can have variable lengths in different tumors (Gonzalez-Zulueta et al. 1993). In one Ta grade II tumor, this locus was expanded while in more advanced tumor tissue, this locus was shortened (Gonzalez-Zulueta et al. 1993). These data indicate that changes to this region may impact this disease and that shorter repeats, and thus increased AR transactivity, may be involved in disease progression. Building on this data, Teng et al. (2010) examined 95 male patients with urothelial carcinoma and found that their polyGln region was significantly shorter than those found in a reference group. These results further support the notion that a shorter polyGln region, and increased AR activity, is involved with bladder cancer etiology and progression.

Several hypotheses can be generated regarding the AR's contribution to bladder cancer based on genetic variation studies. Genome wide association studies (GWAS) have identified a number of small nucleotide polymorphisms (SNPs) which are associated with increased risk of bladder cancer. A number of these SNPs are next to or within genes that have previously been associated with cancer (Golka et al. 2011). Interestingly, several SNPs map to 8q24, a region of the genome that has been described as a gene desert (Huppi et al. 2012). Notably the Myc gene lies at the border of this region (Huppi et al. 2012). The rs $9642880 \mathrm{~T}$ allele, which has been shown to be associated with an increased risk of bladder cancer in North European and Chinese populations (with an odds ratio of 1.22 and 1.64, respectively), maps to this region (Kiemeney et al. 2008, Wang et al. 2009). The SNP lies within the non-protein coding BC042052 gene (aka CASC11, CARLo-5) that has been associated with certain cancers, hence this RNA transcript may contribute to bladder tumorigenesis (Luo et al. 2014, Zhang et al. 2014). The Myc enhancer region physically interacts with the active regulatory region of the CARLo-5 promoter, where long-range interaction of Myc enhancer with the CARLo-5 promoter regulates CARLo-5 expression (Kim et al. 2014). Previous studies have shown that the AR directly controls Myc transcription (Gao et al. 2013). Additional studies found that Myc expression is elevated in bladder cancers (Schmitz-Drager et al. 1997). Therefore, the AR may be

Published by Bioscientifica Ltd 
directly or indirectly affecting the transcription of this non-coding gene by controlling Myc transcription.

Two independent studies have linked a variation within the prostate stem cell antigen (PSCA) gene with increased susceptibility to bladder cancer (Wu et al. 2009, Fu et al. 2012). The rs 2294008 SNP cancer predisposing variant alters the start codon which results in a nine amino acid N-terminal truncation (Wu et al. 2009). The risk allele was associated with increased PSCA mRNA expression in two sets of bladder tumor samples arguing that enhanced PSCA expression contributes to bladder tumorigenesis ( $\mathrm{Fu}$ et al. 2012). Previous studies have shown that PSCA is a direct target of AR therefore AR-dependent increased PSCA could contribute to tumorigenesis (Jain et al. 2002). Further studies are needed to explore this possibility.

Multiple studies have identified bladder cancer susceptibility SNPs in the urea transporter gene, SLC14A1 (Garcia-Closas et al. 2011, Rafnar et al. 2011, Singh et al. 2014, Matsuda et al. 2015). Additional studies found that the rs10775480 risk allele is associated with a significant decrease in urine concentration (Koutros et al. 2013). The data suggest that this urea transporter has the ability to influence urine concentration and ultimately bladder cancer susceptibility. The authors hypothesized that bladder cancer risk might be related to this impaired urine concentrating ability. The SLC14A1 gene is an AR regulated gene that is decreased in prostate cancer tissue hence AR-dependent decrease of SLC14A1 could contribute to bladder carcinogenesis (Vaarala et al. 2012).

\section{The role of the AR in bladder cancer invasion and angiogenesis}

The AR may also contribute to invasive and metastatic disease. CD24, a glycosyl phosphatidylinositol-linked sialoglycoprotein, contributes to tumor growth, metastasis, and is associated with poor outcome in bladder tumorigenesis. The BBN animal model of bladder tumor induction was used to define the importance of CD24 in tumor formation and metastasis. Ablation of CD24 resulted in fewer metastases than in control animals. Interestingly, this result was restricted to male mice, suggesting a role for androgens (Overdevest et al. 2012). In cell culture studies, an AR knockdown resulted in decreased CD24 expression and cell proliferation, while treatment with androgens increased CD24 levels, arguing that CD24 is androgen regulated in urothelial cells (Overdevest et al. 2012). Others have found that androgen stimulation of AR positive bladder cancer cells promoted a mesenchymal phenotype, migration and invasion in vitro, and metastasis in vivo (Jing et al. 2014). Furthermore, it was determined that this effect was mediated via canonical Wnt signaling which activates Slug (Jing et al. 2014). These data were supported in a subsequent study that demonstrated that AR mediated promotion of migration (Jitao et al. 2014).

Angiogenesis is an important feature of tumor development. Thrombospondin-1 (TSP1) is a secreted anti-angiogenic protein that forms a 450-kDa homotrimer (Armstrong \& Bornstein 2003). Studies in the UPII-SV40T mouse model of bladder tumorigenesis showed that castration increased TSP1 in bladder tissue (Johnson et al. 2008). Additionally, studies of human bladder tissue indicated that TSP1 expression is lower in malignant tissue than in non-malignant tissue in the same individual (Johnson et al. 2008). These data argue that one role of the AR in bladder tumorigenesis may be repression of TSP1.

\section{Therapeutic potential of targeting the AR in bladder cancer}

One currently effective treatment for NMIBC is intravesical administration of attenuated mycobacterium bacillus Calmette-Guerin (BCG) which elicits an anti-tumor immune response (Malkowicz 2000). Many patients respond favorably to this treatment (Chen et al. 2003). However, some patients prove to be non-responders and many others relapse following treatment (Chen et al. 2003). Understanding why patients fail to respond and why others relapse could provide opportunities for novel interventions. It is thought that the effectiveness of BCG treatment is in part dependent on its adherence to the urothelial wall via an interaction with $\alpha 5 \beta 1$ integrin (Zhang et al. 2000). Furthermore, it has been shown that BCG treatment results in the upregulation of IL6 which promotes expression of $\alpha 5 \beta 1$ integrin thus allowing BCG to promote its own efficacy (Bevers et al. 1998, Zhang et al. 2000). Chen et al. (2003) demonstrate that androgens inhibit BCG-induced expression of IL6 in the UCCB cell lines 253J and T24. Furthermore, these authors demonstrate that the use of the anti-androgens bicalutamide and hydroxyflutamide can reverse the effects of androgen on inhibition of IL6 expression (Chen et al. 2003). Thus, targeting AR signaling could improve patient responses to BCG treatment.

Efficacy of androgen deprivation therapy (ADT) in attenuating bladder cancer recurrence comes from a study of prostate cancer patients who also had primary bladder cancer of varying grades and stages ranging from Ta to beyond T1 (Izumi et al. 2014). Retrospective analysis of

Published by Bioscientifica Ltd. 
patients who did and did not receive ADT for prostate cancer revealed that men given ADT had longer 5 year recurrence free survival rates and had fewer subsequent recurrences (Izumi et al. 2014). This analysis also found ADT was an independent prognosticator of bladder cancer recurrence and that the effect of ADT on recurrence is time dependent indicating longer treatment periods provide more patient benefit (Izumi et al. 2014). Based on the work presented here, ADT could become a novel way to treat and better prevent recurrence of bladder tumors. Clinical trials are being planned to assess these possibilities (Izumi et al. 2014). This work also suggests that ADT could be effective in treating a range of tumor grades and stages. Whether ADT leads to a decrease in progression of the disease remains to be tested. The BCG data presented earlier leads to the speculation that targeting the AR in early stage bladder cancer along with BCG therapy could lead to even further reduced rates of recurrence. However, this potential treatment strategy needs to be investigated.

Other investigators have also demonstrated the utility in targeting the AR for bladder cancer therapy. Inhibition of AR signaling via castration, small molecule drugs, or combinations of these resulted in decreased proliferation, tumor volume, and tumor weight while also increasing cell death in vivo (Miyamoto et al. 2007). Moreover, there was decreased expression of bFGF, VEGF, and MMP-9, all documented oncogenes in the context of bladder cancer (Miyamoto et al. 2007). In vitro models utilizing the AR positive cell lines TCCSUP and UM-UC-3 and the AR-negative cell line 5637 demonstrated that AR targeting siRNA can also attenuate proliferation of bladder cancer cells but only in AR positive lines (Miyamoto et al. 2007). Interestingly, they found that AR siRNA was more effective than hydroxyflutamide (Miyamoto et al. 2007). Additional studies showed that siRNA-mediated AR inhibition increased apoptosis and decreased proliferation and migration in UCCB cell lines (Wu et al. 2010). This was coincident with a decrease of cyclin D1, BclXL, and MMP9 (Wu et al. 2010). In vivo AR inhibition attenuates tumor growth of $\mathrm{T} 24$ xenografts (Wu et al. 2010). It was also determined that AR inhibition sensitized UM-UC-3 cells to doxorubicin treatment (Shiota et al. 2012). Drawing from these studies, it is reasonable to hypothesize that targeting the AR could prove to be an efficacious treatment not only for early stage disease but also for advanced tumors expressing the AR. Furthermore, one study demonstrated that AR targeting could sensitize bladder tumors to chemotherapy suggesting a rationale for the use of AR antagonists to augment treatment of advanced stage disease.
In addition to more traditionally considered means of targeting the AR for therapy, alternative approaches could prove useful. Given the large number of signaling pathways that intersect with the AR reviewed in a previous section, targeting the AR-interacting components and signaling pathways may indirectly affect AR activity. Targeting of several AR coregulators was shown to inhibit UCCB cell viability suggesting this could be an effective strategy (Boorjian et al. 2009). It was determined that pharmacological inhibition of LSD1, an AR co-regulator mentioned previously which is upregulated in bladder cancer, attenuated viability of bladder cancer cells and decreased androgen-mediated transcription (Kauffman et al. 2011). Other approaches for reducing AR signaling include the utilization of natural compounds found in certain foods that may possess anti-cancer properties. One such compound is silymarin, a flavonoid found in the milk thistle plant (Zhu et al. 2001). It has been demonstrated that silymarin and its primary constituent silibinin can inhibit the activity of androgen signaling and prevents AR nuclear localization in prostate cancer cells (Zhu et al. 2001). It is worth investigating if these findings can translate to bladder cancer for similar therapeutic purposes.

Although there is much evidence that targeting the AR for bladder cancer therapy could prove beneficial, it is important to keep in mind side effects that could ensue from such treatments. Common side effects of ADT include loss of libido, erectile dysfunction, and hot flashes (Higano 2003). Although manageable, these effects can prove rather distressing for suffering patients. More serious side effects include physical symptoms such as gynecomastia as well as the exacerbation of other conditions such as hypertension and diabetes (Higano 2003).

Long term outcomes of a new therapy must also be carefully considered. In the context of prostate cancer, ADT has been shown to promote EMT (Sun et al. 2012). Since studies suggest that the AR and androgen signaling promote EMT, migration, and invasion in bladder tumors and flutamide or an siRNA targeting the AR inhibits these responses, it is reasonable to hypothesize that ADT could be beneficial in the long term for certain patients (Jing et al. 2014, Jitao et al. 2014). However, identifying the patient cohort that would benefit from this intervention should be addressed prior to initiating such therapies.

\section{Final discussion and conclusions}

The work reviewed supports the hypothesis that bladder cancer is in fact an endocrine-related cancer in which AR

Published by Bioscientifica Ltd. 
and androgen signaling play a role in the etiology and progression of the disease. This is not all that surprising given the work highlighting the role of androgen signaling in normal bladder function. This hypothesis provides, at least in part, a reasonable explanation for the glaring disparity of bladder cancer diagnoses between males and females. Scientists and clinicians could begin to view bladder cancer in a new light and traditional therapies used to treat prostate cancer could be used to treat bladder tumors as well. However, questions abound in this burgeoning field requiring additional studies.

A number of studies have demonstrated that the AR is expressed in bladder tumors and is upregulated in comparison to normal tissue. However, significant evidence suggests an inverse relationship between AR expression and advanced disease. AR expression could be biphasic during the course of this disease. This raises the interesting question of when to target the AR for effective bladder cancer treatment and in which patients. Future work must address this question to determine the best time to intervene in this manner. Whether targeting the AR could potentially lead to eventual tumor progression in those patients exhibiting the inverse relationship must be addressed.

A number of studies describe the ways of which the AR promotes bladder cancer progression. AR signaling in bladder cancer affects a number of key facets of the disease including proliferation and migration. Furthermore, the AR and AR signaling can interact with a number of key pathways described in these diseases. This raises the possibility of interesting combination therapies that could be tried. Bladder cancer is a disease with few treatment options and no approved targeted therapies (Cancer Genome Atlas Research Network 2014). Targeting the AR and possibly combining it with other drugs could prove to be a more effective treatment strategy.

Other questions arise when considering whether AR targeting should be adopted as a method to treat bladder malignancies. Would tumors eventually become resistant to such therapies giving rise to castration-resistant bladder cancer (CRBC) similar to castration-resistant prostate cancer (CRPC)? What would such a disease state look like? Would it look like CRPC or be a completely different entity? What mechanisms might drive CRBC and how would this state be overcome?

In conclusion, we have explored the body of evidence that suggests the AR is a participant in bladder tumorigenesis and thus represents a potential target for bladder cancer treatment. However, more work is needed to understand the unique features of AR signaling in bladder tumor cells to determine the efficacy in targeting the AR for treatment of this malignancy.

\section{Declaration of interest}

The authors declare that there is no conflict of interest that could be perceived as prejudicing the impartiality of this review.

\section{Funding}

The US Department of Veterans Affairs, Office of Research and Development, VA MERIT awards BX001079 to M Mudryj partially funded this work. The contents are solely the responsibility of the authors and do not necessarily represent the official view of the VA or the US government.

\section{Acknowledgements}

We thank Rachel Nakagawa for her contributions in reviewing the literature. We thank Rachel Nakagawa, Steve Libertini, and Kathleen Vidallo for critical review of the manuscript.

\section{References}

Ahmadi N, Delprado WJ, Brooks AJ, Brenner PC, Coombes GM, Grant A \& Patel MI 2014 Cancer identified incidentally in the prostate following radical cystoprostatectomy: an Australian study. ANZ Journal of Surgery 84 473-476. (doi:10.1111/ans.12015)

Allen RC, Zoghbi HY, Moseley AB, Rosenblatt HM \& Belmont JW 1992 Methylation of HpaII and HhaI sites near the polymorphic CAG repeat in the human androgen-receptor gene correlates with $\mathrm{X}$ chromosome inactivation. American Journal of Human Genetics 51 1229-1239. (doi:10.3892/or_00000702)

Alsinnawi M, Loftus B, Flynn R, McDermott T, Grainger R \& Thornhill JA 2012 The incidence and relevance of prostate cancer in radical cystoprostatectomy specimens. International Urology and Nephrology $\mathbf{4 4}$ 1705-1710. (doi:10.1007/s11255-012-0224-y)

Armstrong LC \& Bornstein P 2003 Thrombospondins 1 and 2 function as inhibitors of angiogenesis. Matrix Biology 22 63-71. (doi:10.1016/ S0945-053X(03)00005-2)

Augello MA, Burd CJ, Birbe R, McNair C, Ertel A, Magee MS, Frigo DE, WilderRomans K, Shilkrut M, Han S et al. 2013 Convergence of oncogenic and hormone receptor pathways promotes metastatic phenotypes. Journal of Clinical Investigation 123 493-508. (doi:10.1172/JCI64750)

Bevers RF, de Boer EC, Kurth KH \& Schamhart DH 1998 BCG-induced interleukin-6 upregulation and BCG internalization in well and poorly differentiated human bladder cancer cell lines. European Cytokine Network 9 181-186.

Bock KW 2010 Functions and transcriptional regulation of adult human hepatic UDP-glucuronosyl-transferases (UGTs): mechanisms responsible for interindividual variation of UGT levels. Biochemical Pharmacology 80 771-777. (doi:10.1016/j.bcp.2010.04.034)

Boorjian S, Ugras S, Mongan NP, Gudas LJ, You X, Tickoo SK \& Scherr DS 2004 Androgen receptor expression is inversely correlated with pathologic tumor stage in bladder cancer. Urology 64 383-388. (doi:10.1016/j.urology.2004.03.025)

Boorjian SA, Heemers HV, Frank I, Farmer SA, Schmidt LJ, Sebo TJ \& Tindall DJ 2009 Expression and significance of androgen receptor coactivators in urothelial carcinoma of the bladder. Endocrine-Related Cancer 16 123-137. (doi:10.1677/ERC-08-0124)

Bruins HM, Djaladat H, Ahmadi H, Sherrod A, Cai J, Miranda G, Skinner EC \& Daneshmand S 2013 Incidental prostate cancer in patients with

Published by Bioscientifica Ltd 
bladder urothelial carcinoma: comprehensive analysis of 1,476 radical cystoprostatectomy specimens. Journal of Urology 190 1704-1709. (doi:10.1016/j.juro.2013.05.034)

Cancer Genome Atlas Research Network 2014 Comprehensive molecular characterization of urothelial bladder carcinoma. Nature 507 315-322. (doi:10.1038/nature12965)

Carneiro BA, Meeks JJ, Kuzel TM, Scaranti M, Abdulkadir SA \& Giles FJ 2015 Emerging therapeutic targets in bladder cancer. Cancer Treatment Reviews 41 170-178. (doi:10.1016/j.ctrv.2014.11.003)

Chang CS, Kokontis J \& Liao ST 1988 Molecular cloning of human and rat complementary DNA encoding androgen receptors. Science $\mathbf{2 4 0}$ 324-326. (doi:10.1126/science.3353726)

Chang C, Lee SO, Yeh S \& Chang TM 2014 Androgen receptor (AR) differential roles in hormone-related tumors including prostate, bladder, kidney, lung, breast and liver. Oncogene 33 3225-3234. (doi:10.1038/onc.2013.274)

Chen F, Langenstroer P, Zhang G, Iwamoto Y \& See W 2003 Androgen dependent regulation of bacillus Calmette-Guerin induced interleukin-6 expression in human transitional carcinoma cell lines. Journal of Urology 170 2009-2013. (doi:10.1097/01.ju.0000092238.15685.10)

Cheng L, MacLennan GT, Pan CX, Jones TD, Moore CR, Zhang S, Gu J, Patel NB, Kao C \& Gardner TA 2004 Allelic loss of the active X chromosome during bladder carcinogenesis. Archives of Pathology \& Laboratory Medicine 128 187-190.

Crallan RA, Georgopoulos NT \& Southgate J 2006 Experimental models of human bladder carcinogenesis. Carcinogenesis 27 374-381. (doi:10.1093/carcin/bgi266)

Culig Z \& Santer FR 2012 Androgen receptor co-activators in the regulation of cellular events in prostate cancer. World Journal of Urology $\mathbf{3 0}$ 297-302. (doi:10.1007/s00345-011-0797-6)

Devlin HL \& Mudryj M 2009 Progression of prostate cancer: multiple pathways to androgen independence. Cancer Letters 274 177-186. (doi:10.1016/j.canlet.2008.06.007)

Fritsche HM, Aziz A, Eder F, Otto W, Denzinger S, Wieland WF, May M, Hofstadter F, Hartmann A \& Burger M 2012 Potentially clinically relevant prostate cancer is found more frequently after complete than after partial histopathological processing of radical cystoprostatectomy specimens. Virchows Archiv 461 655-661. (doi:10.1007/s00428-012-1328-6)

Fu YP, Kohaar I, Rothman N, Earl J, Figueroa JD, Ye Y, Malats N, Tang W, Liu L, Garcia-Closas M et al. 2012 Common genetic variants in the PSCA gene influence gene expression and bladder cancer risk. PNAS 109 4974-4979. (doi:10.1073/pnas.1202189109)

Gakis G \& Stenzl A 2013 Gender-specific differences in muscle-invasive bladder cancer: the concept of sex steroid sensitivity. World Journal of Urology 31 1059-1064. (doi:10.1007/s00345-013-1037-z)

Gao L, Schwartzman J, Gibbs A, Lisac R, Kleinschmidt R, Wilmot B, Bottomly D, Coleman I, Nelson P, McWeeney S et al. 2013 Androgen receptor promotes ligand-independent prostate cancer progression through c-Myc upregulation. PLoS ONE 8 e63563. (doi:10.1371/journal. pone.0063563)

Garcia-Closas M, Ye Y, Rothman N, Figueroa JD, Malats N, Dinney CP, Chatterjee N, Prokunina-Olsson L, Wang Z, Lin J et al. 2011 A genomewide association study of bladder cancer identifies a new susceptibility locus within SLC14A1, a urea transporter gene on chromosome 18q12.3. Human Molecular Genetics 20 4282-4289. (doi:10.1093/hmg/ddr342)

Golka K, Selinski S, Lehmann ML, Blaszkewicz M, Marchan R, Ickstadt K, Schwender H, Bolt HM \& Hengstler JG 2011 Genetic variants in urinary bladder cancer: collective power of the "wimp SNPs". Archives of Toxicology 85 539-554. (doi:10.1007/s00204-011-0676-3)

Gonzalez-Zulueta M, Ruppert JM, Tokino K, Tsai YC, Spruck CH III, Miyao N, Nichols PW, Hermann GG, Horn T, Steven K et al. 1993 Microsatellite instability in bladder cancer. Cancer Research $\mathbf{5 3}$ $5620-5623$.
Hartge P, Harvey EB, Linehan WM, Silverman DT, Sullivan JW, Hoover RN \& Fraumeni JF Jr 1990 Unexplained excess risk of bladder cancer in men. Journal of the National Cancer Institute 82 1636-1640. (doi:10.1093/jnci/82.20.1636)

Higano CS 2003 Side effects of androgen deprivation therapy: monitoring and minimizing toxicity. Urology 61 32-38. (doi:10.1016/S00904295(02)02397-X)

Hsieh TF, Chen CC, Ma WL, Chuang WM, Hung XF, Tsai YR, Lin MH, Zhang Q, Zhang C, Chang C et al. 2013 Epidermal growth factor enhances androgen receptormediated bladder cancer progression and invasion via potentiation of AR transactivation. Oncology Reports 30 2917-2922. (doi:10.3892/or.2013.2792)

Hsu JW, Hsu I, Xu D, Miyamoto H, Liang L, Wu XR, Shyr CR \& Chang C 2013 Decreased tumorigenesis and mortality from bladder cancer in mice lacking urothelial androgen receptor. American Journal of Pathology 182 1811-1820. (doi:10.1016/j.ajpath.2013.01.018)

Huppi K, Pitt JJ, Wahlberg BM \& Caplen NJ 2012 The 8q24 gene desert: an oasis of non-coding transcriptional activity. Frontiers in Genetics 369. (doi:10.3389/fgene.2012.00069)

Imada S, Akaza H, Ami Y, Koiso K, Ideyama Y \& Takenaka T 1997 Promoting effects and mechanisms of action of androgen in bladder carcinogenesis in male rats. European Urology 31 360-364.

Izumi K, Zheng Y, Li Y, Zaengle J \& Miyamoto H 2012 Epidermal growth factor induces bladder cancer cell proliferation through activation of the androgen receptor. International Journal of Oncology 41 1587-1592. (doi:10.3892/ijo.2012.1593)

Izumi K, Zheng Y, Hsu JW, Chang C \& Miyamoto H 2013 Androgen receptor signals regulate UDP-glucuronosyltransferases in the urinary bladder: a potential mechanism of androgen-induced bladder carcinogenesis. Molecular Carcinogenesis 52 94-102. (doi:10.1002/mc.21833)

Izumi K, Taguri M, Miyamoto H, Hara Y, Kishida T, Chiba K, Murai T, Hirai K, Suzuki K, Fujinami K et al. 2014 Androgen deprivation therapy prevents bladder cancer recurrence. Oncotarget 5 12665-12674.

Jain A, Lam A, Vivanco I, Carey MF \& Reiter RE 2002 Identification of an androgen-dependent enhancer within the prostate stem cell antigen gene. Molecular Endocrinology 16 2323-2337. (doi:10.1210/me.2002-0004)

Jing Y, Cui D, Guo W, Jiang J, Jiang B, Lu Y, Zhao W, Wang X, Jiang Q, Han B et al. 2014 Activated androgen receptor promotes bladder cancer metastasis via Slug mediated epithelial-mesenchymal transition. Cancer Letters 348 135-145. (doi:10.1016/j.canlet.2014.03.018)

Jitao W, Jinchen H, Qingzuo L, Li C, Lei S, Jianming W \& Zhenli G 2014 Androgen receptor inducing bladder cancer progression by promoting an epithelial-mesenchymal transition. Andrologia 46 1128-1133. (doi:10.1111/and.12203)

Johnson AM, O'Connell MJ, Miyamoto H, Huang J, Yao JL, Messing EM \& Reeder JE 2008 Androgenic dependence of exophytic tumor growth in a transgenic mouse model of bladder cancer: a role for thrombospondin-1. BMC Urology 8 7. (doi:10.1186/1471-2490-8-7)

Kauffman EC, Robinson BD, Downes MJ, Powell LG, Lee MM, Scherr DS, Gudas LJ \& Mongan NP 2011 Role of androgen receptor and associated lysine-demethylase coregulators, LSD1 and JMJD2A, in localized and advanced human bladder cancer. Molecular Carcinogenesis 50 931-944. (doi:10.1002/mc.20758)

Kazemi-Esfarjani P, Trifiro MA \& Pinsky L 1995 Evidence for a repressive function of the long polyglutamine tract in the human androgen receptor: possible pathogenetic relevance for the (CAG)n-expanded neuronopathies. Human Molecular Genetics 4 523-527. (doi:10.1093/ $\mathrm{hmg} / 4.4 .523)$

Keast JR \& Saunders RJ 1998 Testosterone has potent, selective effects on the morphology of pelvic autonomic neurons which control the bladder, lower bowel and internal reproductive organs of the male rat. Neuroscience 85 543-556. (doi:10.1016/S0306-4522(97)00631-3)

Kiemeney LA, Thorlacius S, Sulem P, Geller F, Aben KK, Stacey SN, Gudmundsson J, Jakobsdottir M, Bergthorsson JT, Sigurdsson A et al. 2008 Sequence variant on 8q24 confers susceptibility to urinary bladder cancer. Nature Genetics 40 1307-1312. (doi:10.1038/ng.229) 
Kim JJ 2012 Recent advances in treatment of advanced urothelial carcinoma. Current Urology Reports 13 147-152. (doi:10.1007/ s11934-012-0238-0)

Kim T, Cui R, Jeon YJ, Lee JH, Sim H, Park JK, Fadda P, Tili E, Nakanishi H, Huh MI et al. 2014 Long-range interaction and correlation between MYC enhancer and oncogenic long noncoding RNA CARLo-5. PNAS 111 4173-4178. (doi:10.1073/pnas.1400350111)

Kimura N, Mizokami A, Oonuma T, Sasano H \& Nagura H 1993 Immunocytochemical localization of androgen receptor with polyclonal antibody in paraffin-embedded human tissues. Journal of Histochemistry and Cytochemistry 41 671-678. (doi:10.1177/41.5. 8468448)

Knowles MA \& Hurst CD 2015 Molecular biology of bladder cancer: new insights into pathogenesis and clinical diversity. Nature Reviews. Cancer 15 25-41. (doi:10.1038/nrc3817)

Koutros S, Baris D, Fischer A, Tang W, Garcia-Closas M, Karagas MR, Schwenn M, Johnson A, Figueroa J, Waddell R et al. 2013 Differential urinary specific gravity as a molecular phenotype of the bladder cancer genetic association in the urea transporter gene, SLC14A1. International Journal of Cancer 133 3008-3013. (doi:10.1002/ijc.28325)

Lamont KR \& Tindall DJ 2011 Minireview: Alternative activation pathways for the androgen receptor in prostate cancer. Molecular Endocrinology 25 897-907. (doi:10.1210/me.2010-0469)

Laor E, Schiffman ZJ, Braunstein JD, Reid RE, Tolia BM, Koss LG \& Freed SZ 1985 Androgen receptors in bladder tumors. Urology 25 161-163. (doi:10.1016/0090-4295(85)90534-5)

Li Y, Zheng Y, Izumi K, Ishiguro H, Ye B, Li F \& Miyamoto H 2013 Androgen activates $\beta$-catenin signaling in bladder cancer cells. Endocrine-Related Cancer 20 293-304. (doi:10.1530/ERC-12-0328)

Lin C, Yin Y, Stemler K, Humphrey P, Kibel AS, Mysorekar IU \& Ma L 2013 Constitutive $\beta$-catenin activation induces male-specific tumorigenesis in the bladder urothelium. Cancer Research 73 5914-5925. (doi:10.1158/0008-5472.CAN-12-4198)

Lubahn DB, Joseph DR, Sullivan PM, Willard HF, French FS \& Wilson EM 1988 Cloning of human androgen receptor complementary DNA and localization to the X chromosome. Science 240 327-330. (doi:10.1126/ science.3353727)

Luo J, Tang L, Zhang J, Ni J, Zhang HP, Zhang L, Xu JF \& Zheng D 2014 Long non-coding RNA CARLo-5 is a negative prognostic factor and exhibits tumor pro-oncogenic activity in non-small cell lung cancer. Tumour Biology 35 11541-11549. (doi:10.1007/s13277-014-2442-7)

Malkowicz SB 2000 Intravesical therapy for superficial bladder cancer. Seminars in Urologic Oncology 18 280-288.

Marcinkiewicz K, Scotland KB, Boorjian SA, Nilsson EM, Persson JL, Abrahamsson PA, Allegrucci C, Hughes IA, Gudas LJ \& Mongan NP 2012 The androgen receptor and stem cell pathways in prostate and bladder cancers (review). International Journal of Oncology 40 5-12. (doi:10.3892/ijo.2011.1212)

Mashhadi R, Pourmand G, Kosari F, Mehrsai A, Salem S, Pourmand MR, Alatab S, Khonsari M, Heydari F, Beladi L et al. 2014 Role of steroid hormone receptors in formation and progression of bladder carcinoma: a case-control study. Urology Journal 11 1968-1973.

Matsuda K, Takahashi A, Middlebrooks CD, Obara W, Nasu Y, Inoue K, Tamura K, Yamasaki I, Naya Y, Tanikawa C et al. 2015 Genome-wide association study identified SNP on 15q24 associated with bladder cancer risk in Japanese population. Human Molecular Genetics 24 1177-1184. (doi:10.1093/hmg/ddu512)

Matsuki K, Akaza H, Munakata A, Kameyama S \& Aso Y 1989 Effects of LH-RH analogue on pituitary-testicular axis and bladder carcinogenesis of BBN administered male rats. Nihon Hinyokika Gakkai Zasshi. The Japanese Journal of Urology 80 1051-1058. (doi:10.5980/jpnjurol1989. 80.1051)

Matsuki K, Akaza H \& Aso Y 1992 Effects of luteinizing hormone-releasing hormone agonist on bladder carcinogenesis in male rats. Nihon Hinyokika Gakkai Zasshi. The Japanese Journal of Urology 83 1452-1458. (doi:10.5980/jpnjurol1989.83.1452)
Mir C, Shariat SF, van der Kwast TH, Ashfaq R, Lotan Y, Evans A, Skeldon S, Hanna S, Vajpeyi R, Kuk C et al. 2011 Loss of androgen receptor expression is not associated with pathological stage, grade, gender or outcome in bladder cancer: a large multi-institutional study. BJU International 108 24-30. (doi:10.1111/j.1464-410X.2010.09834.X)

Miyamoto H, Yang Z, Chen YT, Ishiguro H, Uemura H, Kubota Y, Nagashima Y, Chang YJ, Hu YC, Tsai MY et al. 2007 Promotion of bladder cancer development and progression by androgen receptor signals. Journal of the National Cancer Institute 99 558-568. (doi:10.1093/ jnci/djk113)

Miyamoto H, Yao JL, Chaux A, Zheng Y, Hsu I, Izumi K, Chang C, Messing EM, Netto GJ \& Yeh S 2012 Expression of androgen and oestrogen receptors and its prognostic significance in urothelial neoplasm of the urinary bladder. BJU International 109 1716-1726. (doi:10.1111/j.1464-410X.2011.10706.x)

Mizuno T 1994 Aspects of morphogenesis and cytodifferentiation of endoderm offered by organ culture techniques. International Journal of Developmental Biology 38 267-272.

Mohanty SK, Smith SC, Chang E, Luthringer DJ, Gown AM, Aron M \& Amin MB 2014 Evaluation of contemporary prostate and urothelial lineage biomarkers in a consecutive cohort of poorly differentiated bladder neck carcinomas. American Journal of Clinical Pathology 142 173-183. (doi:10.1309/AJCPK1OV6IMNPFGL)

Mudryj M \& Tepper CG 2013 On the origins of the androgen receptor low molecular weight species. Hormones \& Cancer 4 259-269. (doi:10.1007/ s12672-013-0152-z)

Nakamura A, Nakajima M, Yamanaka H, Fujiwara R \& Yokoi T 2008 Expression of UGT1A and UGT2B mRNA in human normal tissues and various cell lines. Drug Metabolism and Disposition: The Biological Fate of Chemicals 36 1461-1464. (doi:10.1124/dmd.108.021428)

Nevoux P, Ouzzane A, Ahmed HU, Emberton M, Montironi R, Presti JC Jr \& Villers A 2012 Quantitative tissue analyses of prostate cancer foci in an unselected cystoprostatectomy series. BJU International 110 517-523. (doi:10.1111/j.1464-410X.2011.10776.x)

Noronha RF \& Rao BR 1986 Sex hormone receptors in localized and advanced transitional cell carcinoma of urinary tract in humans. Urology 28 401-403. (doi:10.1016/0090-4295(86)90073-7)

Okajima E, Hiramatsu T, Iriya K, Ijuin M \& Matsushima S 1975 Effects of sex hormones on development of urinary bladder tumours in rats induced by $N$-butyl-N-(4-hydroxybutyl) nitrosamine. Urological Research $\mathbf{3}$ 73-79. (doi:10.1007/BF00256185)

Overdevest JB, Knubel KH, Duex JE, Thomas S, Nitz MD, Harding MA, Smith SC, Frierson HF, Conaway M \& Theodorescu D 2012 CD24 expression is important in male urothelial tumorigenesis and metastasis in mice and is androgen regulated. PNAS 109 E3588-E3596. (doi:10.1073/pnas.1113960109)

Petre-Draviam CE, Cook SL, Burd CJ, Marshall TW, Wetherill YB \& Knudsen KE 2003 Specificity of cyclin D1 for androgen receptor regulation. Cancer Research 63 4903-4913.

Pour PM \& Stepan K 1987 Induction of prostatic carcinomas and lower urinary tract neoplasms by combined treatment of intact and castrated rats with testosterone propionate and $\mathrm{N}$-nitrosobis(2-oxopropyl)amine. Cancer Research 47 5699-5706.

Powles T, Eder JP, Fine GD, Braiteh FS, Loriot Y, Cruz C, Bellmunt J, Burris HA, Petrylak DP, Teng SL et al. 2014 MPDL3280A (anti-PD-L1) treatment leads to clinical activity in metastatic bladder cancer. Nature 515 558-562. (doi:10.1038/nature13904)

Proverbs-Singh T, Feldman JL, Morris MJ, Autio KA \& Traina TA 2015 Targeting the androgen receptor in prostate and breast cancer: several new agents in development. Endocrine-Related Cancer 22 R87-R106. (doi:10.1530/ERC-14-0543)

Rafnar T, Vermeulen SH, Sulem P, Thorleifsson G, Aben KK, Witjes JA Grotenhuis AJ, Verhaegh GW, Hulsbergen-van de Kaa CA, Besenbacher S et al. 2011 European genome-wide association study identifies SLC14A1 as a new urinary bladder cancer susceptibility gene. Human Molecular Genetics 20 4268-4281. (doi:10.1093/hmg/ddr303) 
Ren B, Li W, Yang Y \& Wu S 2014 The impact of cyclin D1 overexpression on the prognosis of bladder cancer: a meta-analysis. World Journal of Surgical Oncology 12 55. (doi:10.1186/1477-7819-12-55)

Ruizeveld de Winter JA, Trapman J, Vermey M, Mulder E, Zegers ND \& van der Kwast TH 1991 Androgen receptor expression in human tissues: an immunohistochemical study. Journal of Histochemistry and Cytochemistry 39 927-936. (doi:10.1177/39.7.1865110)

Saikawa S, Kanamura H, Noriki S, Matsukawa S \& Okada K 2001 The effects of organ resection on rat urinary bladder carcinogenesis. Urological Research 29 210-215. (doi:10.1007/s002400100184)

Salmi S, Santti R, Gustafsson JA \& Makela S 2001 Co-localization of androgen receptor with estrogen receptor $\beta$ in the lower urinary tract of the male rat. Journal of Urology 166 674-677. (doi:10.1016/S0022$5347(05) 66041-7)$

Schmitz-Drager BJ, Schulz WA, Jurgens B, Gerharz CD, vanRoeyen CR, Bultel H, Ebert T \& Ackermann R 1997 c-myc in bladder cancer. Clinical findings and analysis of mechanism. Urological Research 25 (Suppl 1) S45-S49. (doi:10.1007/BF00942047)

Shiota M, Takeuchi A, Yokomizo A, Kashiwagi E, Tatsugami K, Kuroiwa K \& Naito S 2012 Androgen receptor signaling regulates cell growth and vulnerability to doxorubicin in bladder cancer. Journal of Urology $\mathbf{1 8 8}$ 276-286. (doi:10.1016/j.juro.2012.02.2554)

Shortliffe LM, Ye Y, Behr B \& Wang B 2014 Testosterone changes bladder and kidney structure in juvenile male rats. Journal of Urology 191 1913-1919. (doi:10.1016/j.juro.2014.01.012)

Siegel R, Naishadham D \& Jemal A 2012 Cancer statistics, 2012. CA: A Cancer Journal for Clinicians 62 10-29. (doi:10.3322/caac.20138)

Singh V, Jaiswal PK \& Mittal RD 2014 Replicative study of GWAS TP63C/T, TERTC/T, and SLC14A1C/T with susceptibility to bladder cancer in North Indians. Urologic Oncology 32 1209-1214. (doi:10.1016/j.urolonc. 2014.05.013)

Sun Y, Wang BE, Leong KG, Yue P, Li L, Jhunjhunwala S, Chen D, Seo K, Modrusan Z, Gao WQ et al. 2012 Androgen deprivation causes epithelial-mesenchymal transition in the prostate: implications for androgen-deprivation therapy. Cancer Research 72 527-536. (doi:10.1158/0008-5472.CAN-11-3004)

Teng XY, Liu GQ, Diao XL, Wu ZY, Li L, Zhang W, Zhang X \& Su Q 2010 CAG repeats in the androgen receptor gene are shorter in patients with pulmonary, esophageal or bladder carcinoma and longer in women with uterine leiomyoma. Oncology Reports 23 811-818. (doi:10.3892/ or_0000070)

Terada S, Suzuki N, Uchide K, Akasofu K \& Nishida E 1992 Effect of testosterone on the development of bladder tumors and calculi in female rats. Gynecologic and Obstetric Investigation 34 105-110. (doi:10.1159/000292737)

Thomas JC, Oottamasathien S, Makari JH, Honea L, Sharif-Afshar AR, Wang Y, Adams C, Wills ML, Bhowmick NA, Adams MC et al. 2008 Temporal-spatial protein expression in bladder tissue derived from embryonic stem cells. Journal of Urology 180 1784-1789. (doi:10.1016/ j.juro.2008.03.098)

Trapman J, Klaassen P, Kuiper GG, van der Korput JA, Faber PW, van Rooij HC, Geurts van Kessel A, Voorhorst MM, Mulder E \& Brinkmann AO 1988 Cloning, structure and expression of a cDNA encoding the human androgen receptor. Biochemical and Biophysical Research Communications 153 241-248. (doi:10.1016/S0006-291X(88)81214-2)

Turkeri LN, Erton ML, Cevik I \& Akdas A 1998 Impact of the expression of epidermal growth factor, transforming growth factor $\alpha$, and epidermal growth factor receptor on the prognosis of superficial bladder cancer. Urology 51 645-649. (doi:10.1016/S0090-4295(97) 00648-1)

Tuygun C, Kankaya D, Imamoglu A, Sertcelik A, Zengin K, Oktay M \& Sertcelik N 2011 Sex-specific hormone receptors in urothelial carcinomas of the human urinary bladder: a comparative analysis of clinicopathological features and survival outcomes according to receptor expression. Urologic Oncology 29 43-51. (doi:10.1016/j. urolonc.2009.01.033)

Vaarala MH, Hirvikoski P, Kauppila S \& Paavonen TK 2012 Identification of androgen-regulated genes in human prostate. Molecular Medicine Reports 6 466-472. (doi:10.3892/mmr.2012.95)

Wang M, Zhang W, Yuan L, Fu G, Wei Q \& Zhang Z 2009 Common genetic variants on $8 \mathrm{q} 24$ contribute to susceptibility to bladder cancer in a Chinese population. Carcinogenesis 30 991-996. (doi:10.1093/carcin/ bgp091)

Wen J, Li HZ, Ji ZG \& Jin J 2015 Human urothelial carcinoma cell response to Sunitinib malate therapy in vitro. Cancer Cell International 1526. (doi:10.1186/s12935-015-0179-z)

Williams EM, Higgins JP, Sangoi AR, McKenney JK \& Troxell ML 2015 Androgen receptor immunohistochemistry in genitourinary neoplasms. International Urology and Nephrology 47 81-85. (doi:10.1007/ s11255-014-0834-7)

Wu X, Ye Y, Kiemeney LA, Sulem P, Rafnar T, Matullo G, Seminara D, Yoshida T, Saeki N, Andrew AS et al. 2009 Genetic variation in the prostate stem cell antigen gene PSCA confers susceptibility to urinary bladder cancer. Nature Genetics 41 991-995. (doi:10.1038/ng.421)

Wu JT, Han BM, Yu SQ, Wang HP \& Xia SJ 2010 Androgen receptor is a potential therapeutic target for bladder cancer. Urology 75 820-827. (doi:10.1016/j.urology.2009.10.041)

Zhang GJ, Crist SA, McKerrow AK, Xu Y, Ladehoff DC \& See WA 2000 Autocrine IL- 6 production by human transitional carcinoma cells upregulates expression of the $\alpha 5 \beta 1$ firbonectin receptor. Journal of Urology 163 1553-1559. (doi:10.1016/S0022-5347(05)67678-1)

Zhang Y, Ma M, Liu W, Ding W \& Yu H 2014 Enhanced expression of long noncoding RNA CARLo-5 is associated with the development of gastric cancer. International Journal of Clinical and Experimental Pathology $\mathbf{7}$ 8471-8479.

Zheng Y, Izumi K, Yao JL \& Miyamoto H 2011 Dihydrotestosterone upregulates the expression of epidermal growth factor receptor and ERBB2 in androgen receptor-positive bladder cancer cells. EndocrineRelated Cancer 18 451-464. (doi:10.1530/ERC-11-0010)

Zhu W, Zhang JS \& Young CY 2001 Silymarin inhibits function of the androgen receptor by reducing nuclear localization of the receptor in the human prostate cancer cell line LNCaP. Carcinogenesis 22 1399-1403. (doi:10.1093/carcin/22.9.1399)

Zhuang YH, Blauer M, Tammela T \& Tuohimaa P 1997 Immunodetection of androgen receptor in human urinary bladder cancer. Histopathology 30 556-562. (doi:10.1046/j.1365-2559.1997.5610801.x)

Received 23 July 2015

Accepted 30 July 2015

Made available online as an Accepted Preprint

30 July 2015 http://erc.endocrinology-journals.org DOI: 10.1530/ERC-15-0209
(C) 2015 Society for Endocrinology Printed in Great Britain
Published by Bioscientifica Ltd 